\title{
Does obesity increase the risk of hepatocellular carcinoma in chronic hepatitis B patients?
}

\author{
Byoung Kuk Jang \\ Department of Internal Medicine, Keimyung University School of Medicine, Daegu, Korea
}

Keywords: Obesity; Metablolic syndrome; Chronic hepatitis B; Hepatocellular carcinoma

\section{See Article on Page 339}

Many studies revealed that obesity was a risk factor for various cancers including hepatocellular carcinoma (HCC). ${ }^{1}$ In a cohort study with a population of around 900,000, males with $35 \mathrm{~kg} / \mathrm{m}^{2}$ or higher body mass index (BMI) had 4.4 times as high dying risk from liver cancer as the control group with normal BMI (18.5 -24.9 $\left.\mathrm{kg} / \mathrm{m}^{2}\right) .{ }^{2}$ According to a recent meta-analysis, the relative risk of liver cancer was $1.17 \%$ in overweight patients and $1.89 \%$ in obese patients compared to normal weight controls. ${ }^{3}$ Furthermore, obesity can be a cause of metabolic syndromes including insulin resistance and type 2 diabetes as well as a broad spectrum of nonalcoholic fatty liver diseases (NAFLD) including simple steatosis, non-alcoholic steatohepatitis (NASH), and cirrhosis. ${ }^{4}$ A populationbased case control study showed that diabetes tripled the HCC risk, ${ }^{5}$ and in another large prospective cohort study, the hazard ratio of HCC was 2.16. ${ }^{6}$ Furthermore, the correlation between diabetes and HCC was verified through various meta-analyses. ${ }^{7.8}$ The NAFLD which is a hepatic manifestation of metabolic syndrome was recently found to develop into cirrhosis and cause HCC, and it was regarded as the main cause of cryptogenic cirrhosis. ${ }^{9-11}$

Chronic hepatitis B (CHB) is one of the most important causes of HCC, accounting for around $60 \%$ in Africa and Asia and around $20 \%$ in western countries. ${ }^{12}$ Among the patients infected by hepatitis B virus (HBV) in Asia, the incidence rate of HCC is estimated to be $0.2 \%$ per year in inactive carriers, $0.6 \%$ in chronic hepatitis without cirrhosis patients, and $3.7 \%$ in compensated cirrhosis patients. ${ }^{13}$ It is generally known that HBV-infected subjects have around 100 times as high risk of $\mathrm{HCC}$ as uninfected subjects. ${ }^{14} \mathrm{~A}$ large prospective cohort study has shown that HBV DNA titer is closely associated with HCC risk. ${ }^{15}$ Many meta-analyses already have revealed that nucleos(t)ide analogues (NAs) decrease the occurrence of HCC in CHB patients. ${ }^{16,17}$ A recent study on CHB patients treated with entecavir (ETV) showed that 5 year HCC incidence rate was decreased significantly by $3.7 \%$ in the ETV treated group compare to $13.7 \%$ in the historical matched untreated control group. ${ }^{18}$

However, unlike chronic hepatitis C (CHC), it is not clear whether obesity is associated with the development of HCC in CHB patients. In a study in Taiwan which followed up 23,820 persons for 14 years, anti-HCV seropositive people with obesity of $30 \mathrm{~kg} /$ $\mathrm{m}^{2}$ or higher BMI had four times higher risk of HCC, and people with no hepatitis B virus (HBV) and hepatitis C virus (HCV) infections had twice higher risk of HCC. ${ }^{19}$ However, obesity was not correlated with HCC risk in HBs antigen seropositive people. Dia-

\section{Abbreviations:}

$\mathrm{BMI}$, body mass index; $\mathrm{CHB}$, Chronic hepatitis $\mathrm{B} ; \mathrm{CHC}$, chronic hepatitis C; ETV, entecavir; HBV, hepatitis B virus; HCV, hepatitis C virus; HCC, hepatocellular carcinoma; NAFLD, non-alcoholic fatty liver disease; $\mathrm{NASH}$, non-alcoholic steatohepatitis; NAs, nucleos(t)ide analogs

\section{Corresponding author : Byoung Kuk Jang}

Department of Internal Medicine, Keimyung University Dongsan Hospital, 56 dalsung-ro, Jung-gu, Daegu 41931, Korea

Tel: +82-53-250-7088, Fax: +82-53-250-7422

E-mail: jangha106@dsmc.or.kr 
betes was associated with HCC in all groups. Thus, HBV-related $\mathrm{HCC}$ risk was more correlated with diabetes (adjusted $\mathrm{OR}=2.27$, $95 \% \mathrm{Cl}: 1.10-4.66$ ) than with extreme obesity (adjusted OR $=1.36$, $95 \%$ Cl: $0.64-2.89)^{19}$

This study by Lee et al. investigated the effects of obesity on HCC development in a total of 102 CHB patients who had been treated with ETV. The median follow-up duration was 45.2 (interquartile range: $36.0-58.3$ ) months, and the 1 year, 3 years, and 5 years cumulative incidence rates of $\mathrm{HCC}$ were $0 \%, 5.3 \%$, and 9.0\%. In univariable analysis, the risk factors of $\mathrm{HCC}$ development were platelet count $<120,000 / \mathrm{mm}^{2}$ (HR 5.21, $P=0.031$ ), HBeAg negativity (HR 5.61, $P=0.039$ ), and liver cirrhosis (HR 10.26, $P=0.031$ ). In multivariable analysis, only liver cirrhosis (HR 9.07, $P=0.042$ ) was a significant risk factor of HCC development. The obesity-related risk factors BMI $\geq 25 \mathrm{~kg} / \mathrm{m}^{2}$ (HR 0.90, $P=0.894$ ), waist circumference $\geq 90 \mathrm{~cm}$ (HR 1.10, $P=0.912$ ), waist-to-hip ratio $\geq 0.9$ (HR 1.94, $P=0.386$ ), visceral fat area $\geq 100 \mathrm{~cm}^{2}$ (HR 1.69, $P=0.495$ ), and hepatic steatosis (HR 0.57, $P=0.602$ ) had no significant correlation with HCC development. However, a few limitations of this study must be mentioned. The first is that as stated above, the number of patients was too small and the follow-up period was too short to examine the effects of obesity on HCC development in patients with CHB which is a strong risk factor of HCC development. The incident cases of HCC were only $7(9 \%)$, the cases who had diabetes were only $4(4 \%)$, and the cases who had metabolic syndrome were only $16(16 \%)$. The second limitation is that a lot of cirrhosis patients were included in whom most cases of HCC developed. However, as it is wellknown that metabolic factors such as obesity Only a few cases of obesity were included disappear once NAFLD patients develop cirrhosis, ${ }^{20}$ Only a few cases of obesity were included in cirrhosis patients. However, data about this is not detailed in the results of this study. The third limitation of this study is that according to the baseline characteristics, the median BMI of enrolled patients is 23.6 $\pm 3.1 \mathrm{~kg} / \mathrm{m}^{2}$, but the numbers of patients with higher BMI more than $25 \mathrm{~kg} / \mathrm{m}^{2}$ or $30 \mathrm{~kg} / \mathrm{m}^{2}$ are not clearly stated.

In the Taiwan cohort study that was introduced above, antiviral treatment for patients with CHB is not mentioned. Therefore, the effects of obesity and similar metabolic factors on CHB patients who develop HCC in relatively younger ages than patients with CHC are estimated to be smaller. However, if serum HBV DNA continued to be negative by antiviral treatment, it would decrease the progression into cirrhosis and HCC. Thus, the effects of obesity and other metabolic factors could be increased on HCC development.
In conclusion, the authors reported that obesity had no correlation with $\mathrm{HCC}$ development in $\mathrm{CHB}$ patients unlike in $\mathrm{CHC}$ patients, but it is not definite. It is especially unknown about the effects of obesity or other metabolic factors on HCC development in CHB patients treated with NAs. In this retrospective study, no correlation was found between $\mathrm{HCC}$ development and obesity related factors in ETV treated CHB patients, but this study is insufficient for making a conclusion. A long-term cohort study of a much greater scale than those of existing studies would be required to clearly determine the correlation.

\section{Conflicts of Interest}

The author has no conflicts to disclose.

\section{REFERENCES}

1. Haslam DW, James WP. Obesity. Lancet 2005;366:1197-1209.

2. Calle EE, Rodriguez C, Walker-Thurmond K, Thun MJ. Overweight, obesity, and mortality from cancer in a prospectively studied cohort of U.S. adults. N Engl J Med 2003;348:1625-1638.

3. Larsson SC, Wolk A. Overweight, obesity and risk of liver cancer: a meta-analysis of cohort studies. Br J Cancer 2007;97:1005-1008.

4. Diehl AM. Hepatic complications of obesity. Gastroenterol Clin North Am 2010;39:57-68.

5. Davila JA, Morgan RO, Shaib Y, McGlynn KA, El-Serag HB. Diabetes increases the risk of hepatocellular carcinoma in the United States: a population based case control study. Gut 2005;54:533-539.

6. El-Serag HB, Tran T, Everhart JE. Diabetes increases the risk of chronic liver disease and hepatocellular carcinoma. Gastroenterology 2004;126:460-468

7. El-Serag HB, Hampel H, Javadi F. The association between diabetes and hepatocellular carcinoma: a systematic review of epidemiologic evidence. Clin Gastroenterol Hepatol 2006;4:369-380.

8. Wang P, Kang D, Cao W, Wang Y, Liu Z. Diabetes mellitus and risk of hepatocellular carcinoma: a systematic review and meta-analysis. Diabetes Metab Res Rev 2012;28:109-122.

9. White DL, Kanwal F, El-Serag HB. Association Between nonalcoholic fatty liver disease and risk for hepatocellular cancer, based on systematic review. Clin Gastroenterol Hepatol 2012;10:1342-1359.

10. Caldwell SH, Oelsner DH, lezzoni JC, Hespenheide EE, Battle EH, Driscoll CJ. Cryptogenic cirrhosis: clinical characterization and risk factors for underlying disease. Hepatology 1999;29:664-669.

11. Marrero JA, Fontana RJ, Su GL, Conjeevaram HS, Emick DM, Lok AS. NAFLD may be a common underlying liver disease in patients with hepatocellular carcinoma in the United States. Hepatology 2002;36:1349-1354

12. European Association For The Study Of The Liver; European Organ- 
isation For Research And Treatment Of Cancer. EASL-EORTC clinical practice guidelines: management of hepatocellular carcinoma. J Hepatol 2012;56:908-943.

13. Fattovich G, Bortolotti F, Donato F. Natural history of chronic hepatitis $B$ : special emphasis on disease progression and prognostic factors. J Hepatol 2008;48:335-352.

14. Beasley RP, Hwang LY, Lin CC, Chien CS. Hepatocellular carcinoma and hepatitis B virus. A prospective study of 22,707 men in Taiwan. Lancet 1981;2:1129-1133.

15. Chen CJ, Yang HI, Su J, Jen CL, You SL, Lu SN, et al. Risk of hepatocellular carcinoma across a biological gradient of serum hepatitis $B$ virus DNA level. JAMA 2006;295:65-73.

16. Singal AK, Salameh H, Kuo YF, Fontana RJ. Meta-analysis: the impact of oral anti-viral agents on the incidence of hepatocellular carcinoma in chronic hepatitis B. Aliment Pharmacol Ther 2013;38:
98-106.

17. Sung JJ, Tsoi KK, Wong VW, Li KC, Chan HL. Meta-analysis: Treatment of hepatitis B infection reduces risk of hepatocellular carcinoma. Aliment Pharmacol Ther 2008;28:1067-1077.

18. Hosaka T, Suzuki F, Kobayashi M, Seko Y, Kawamura Y, Sezaki H, et al. Long-term entecavir treatment reduces hepatocellular carcinoma incidence in patients with hepatitis B virus infection. Hepatology 2013;58:98-107.

19. Chen CL, Yang HI, Yang WS, Liu CJ, Chen PJ, You SL, et al. Metabolic factors and risk of hepatocellular carcinoma by chronic hepatitis B/C infection: a follow-up study in Taiwan. Gastroenterology 2008:135:111-121.

20. Poonawala A, Nair SP, Thuluvath PJ. Prevalence of obesity and diabetes in patients with cryptogenic cirrhosis: a case-control study. Hepatology 2000;32:689-692. 